6a P. S. Bryan and Robert L. Kuczkowski, Inorg. Chem. 11, 553 (1972), report 4.99 $\pm 0.2 \mathrm{D}$ for $\left(\mathrm{CH}_{8}\right)_{3} \mathrm{PBH}_{3}$ and $4.66 \pm 0.05 \mathrm{D}$ for $\mathrm{CH}_{3} \mathrm{PH}_{2} \mathrm{BH}_{3}$.

${ }^{7}$ D. R. Lide, Jr., J. Chem. Phys. 27, 343 (1957); 20, 1812 (1952).

${ }^{8}$ (a) D. R. Lide, Jr., and D. E. Mann, J. Chem. Phys. (a) 28, 572 (1958). (b) 29,914 (1958).
${ }^{9}$ R. J. W. LeFevre and P. Russell, Trans. Faraday Soc. 43, 374 (1947).

${ }^{10}$ T. Kojima, E. Breig, and C. C. Lin, J. Chem. Phys. 35, 2139 (1961).

${ }_{11}$ R. Nelson, J. Chem. Phys. 39, 2382 (1963).

12 R. F. Hudson, Siructure and Mechanism in Organophosphorus Chemistry (Academic, New York, 1965).

\title{
Dipole Moment Studies. VI. Dipole Moments of the Propylphosphines
}

\author{
Joseph G. Morse and R. W. Parry* \\ Department of Chemistry, The University of Michigan, Ann Arbor, Michigan and Department of Chemistry, \\ Utah State University, Logan, Utah 84321
}

(Received 21 April 1972)

\begin{abstract}
The dipole moments of mono-n-propylphosphine and mono- $i$-propylphosphine, as measured in the gas phase with a heterodyne beat apparatus, are $1.09 \pm 0.06$ and $1.22 \pm 0.03 \mathrm{D}$, respectively. The moments of mono- $n$-propylphosphine, di- $n$-propylphosphine, and tri- $n$-propylphosphine as measured in benzene solution and corrected for solvent effect are $1.17 \pm 0.05,1.22 \pm 0.05$, and $1.16 \pm 0.08 \mathrm{D}$, respectively. The moments for mono-i-propylphosphine, di-i-propylphosphine, and tri-i-propylphosphine as measured in benzene solution and corrected for solvent effects are $1.13 \pm 0.03,1.32 \pm 0.12$, and $1.32 \pm 0.04 \mathrm{D}$, respectively. Discrepancies between gas phase and solution values are considered, and values for each series are discussed in terms of a bond polarization model.
\end{abstract}

Earlier papers in this series ${ }^{1-4}$ reported values for the dipole moments of the ethylphosphines and the methylamine boranes. A polarization-bond moment-lone-pair moment model was used to interpret the data and to explain striking contrasts in the trends for the dipole moments of the alkylamines and alkylphosphines. ${ }^{4}$ The present paper provides dipole moment data on the $n$-propyl- and the $i$-propylphosphines thus permitting an extension of the model.

The literature ${ }^{5}$ contains the value $1.48 \mathrm{D}$ as the moment for tri- $n$-propylphosphine, but no values for other members of the series. Because of problems in measuring precise moments for all members of this series by any available technique, the entire series has been reexamined by a single procedure using methods which have been effectively applied to the lighter members of the phosphine series. As the data clearly show, some uncertainty remains in the measurements of the propylphosphines but trends are clearly apparent.

The experimental moments of the mono- $n$-propylphosphine and the mono-i-propylphosphine have been measured in the vapor state. Comparable measurements on the monopropylphosphines in solution provide an evaluation of available solution correction procedures. ${ }^{1}$ Measurements on both of the di- and on both of the tripropylphosphines had to be made in benzene solution because of low sample volatility. No vapor phase comparison was possible on these four molecules. Because of the complexity of the propylphosphines, precise microwave dipole values are not yet available for any member of the series. The microwave problem is definitely not trivial and has not yet been solved.

\section{RESULTS}

\section{Gas Phase Measurements on Primary Propylphosphines}

Gas phase data were reduced by plotting molar polarization of the gas against the inverse of the temperature (Debye method). Details are given in the experimental section. The rather large standard error limits given for the gas phase measurements, particularly for $n-\mathrm{C}_{3} \mathrm{H}_{7} \mathrm{PH}_{2}$, are a result of the low volatility of the phosphine and of some adsorption of the vapor in the vacuum system.

\section{Solution Measurements on Propylphosphines}

Molecular dipole moments were calculated using the standard expression $\mu=0.2212\left(P_{0}\right)^{1 / 2}$, where $P_{0}$ is the orientation polarization; this was obtained as described in the experimental section. The resulting values, which include no correction for solvent effect, are referred to as conventional moments and are listed in Table $I$ as $\mu_{\text {conv }}$. Standard error limits represent precision, not accuracy. These conventional values were corrected for solvent effects using two procedures: (1) the spherical cavity model of Onsager ${ }^{6}$ and (2) the elliptical cavity model of Ref. 1 . Known values for the dielectric constant of the solvent and measured values for the distortion polarization of both solvent and solute were used. The shape of the elliptical cavity used in Method 2 is important since it compensates in part for moments induced in the solvent by the polar solute. Parameters for the cavity were taken from bond angles, bond 
TABLE I. Dipole moment values for the propylphosphines.

\begin{tabular}{|c|c|c|c|c|c|}
\hline \multirow[b]{3}{*}{ Compound } & \multirow{3}{*}{$\begin{array}{c}\text { Gas phase } \\
\mu_{\text {Gas }} \\
\text { debyes }\end{array}$} & \multicolumn{4}{|c|}{ Solution measurements } \\
\hline & & \multirow{2}{*}{$\begin{array}{c}\text { No solv. corr. } \\
\mu_{\operatorname{conv}} \\
\text { debyes }\end{array}$} & \multicolumn{3}{|c|}{ Corrected for solvent effect } \\
\hline & & & $\begin{array}{c}\mu_{\text {apher }} \\
\text { debyes }\end{array}$ & $\begin{array}{c}\mu_{\text {ell }} \\
\text { debyes }\end{array}$ & Shape ellipse \\
\hline$\left(n-\mathrm{C}_{3} \mathrm{H}_{7}\right) \mathrm{H}_{2} \mathrm{P}$ & $1.09 \pm 0.06$ & $1.09 \pm 0.04$ & $1.11 \pm 0.05$ & $1.17 \pm 0.05$ & $b=c ; b / a=0.69$ \\
\hline$\left(n-\mathrm{C}_{3} \mathrm{H}_{7}\right)_{2} \mathrm{HP}$ & & $1.23 \pm 0.04$ & $1.25 \pm 0.05$ & $1.22 \pm 0.05$ & $a=c ; b / a=1.47$ \\
\hline$\left(n-\mathrm{C}_{3} \mathrm{H}_{7}\right)_{3} \mathrm{P}$ & & $1.26 \pm 0.07$ & $1.27 \pm 0.05$ & $1.16 \pm 0.08$ & $b=c ; b / a=2.10$ \\
\hline$\left(i-\mathrm{C}_{3} \mathrm{H}_{7}\right) \mathrm{H}_{2} \mathrm{P}$ & $1.22 \pm 0.05$ & $1.07 \pm 0.03$ & $1.09 \pm 0.05$ & $1.13 \pm 0.04$ & $b=c ; b / a=0.79$ \\
\hline$\left(i-\mathrm{C}_{3} \mathrm{H}_{7}\right)_{2} \mathrm{HP}$ & & $1.34 \pm 0.12$ & $1.36 \pm 0.12$ & $1.32 \pm 0.12$ & $a=c ; b / a=1.60$ \\
\hline$\left(i-\mathrm{C}_{3} \mathrm{H}_{7}\right)_{3} \mathrm{P}$ & & $1.36 \pm 0.03$ & $1.37 \pm 0.04$ & $1.32 \pm 0.04$ & $b=c ; b / a=1.33$ \\
\hline
\end{tabular}

lengths, and van der Waal's radii. The cavity was assumed to be that ellipsoid of revolution indicated by molecular geometry. Experimental values for both gas and solution measurements are summarized in Table $\mathrm{I}$.

Earlier measurements ${ }^{2}$ on $\mathrm{C}_{2} \mathrm{H}_{5} \mathrm{PH}_{2}$ gave a value of $1.17 \pm 0.02$ for the vapor and $1.15 \pm 0.05 \mathrm{D}$ for the solution. Discrepancies on the propylphosphines are larger (Table I). For $n$-propylphosphine the difference is $0.08 \mathrm{D}$; for $i$-propylphosphine the difference is $0.09 \mathrm{D}$. It is, however, important to note that the vapor phase measurements in this study are less certain because of low volatility, and solution measurements are less accurate because of uncertainties in the molecular geometry, cavity shape, and solvent-solute interaction. It is apparent in Table I that for all secondary and tertiary phosphines except tri-n-propylphosphine, the difference between spherical and elliptical corrections is small and has no major influence on the trends observed. On the other hand, models for tri- $n$-propylphosphine show that in most conformations the molecule has a distinctly elliptical shape, hence the difference between the elliptical and spherical correction is expected and reasonable.

In Fig. 1 the vapor phase and solution values (elliptical cavity correction) are plotted for phosphine and all of the primary, secondary, and tertiary phosphines for which reliable data are available. Values for the methylphosphines are literature values from microwave studies and are of highest accuracy. The other primary alkylphosphines are vapor phase measurements from this laboratory and are free of solvent effects. These points are filled in on Fig. 1. The corrected solution values from this laboratory appear as open points. The consistency of trends using solution values corrected for solvent effects adds credence to the "elliptical cavity" correction procedure.

\section{DISCUSSION}

An analysis of dipole trends in amines and phosphines by Yoneda ${ }^{7}$ and by Weaver and Parry, ${ }^{4}$ ascribed a large lone pair moment to the nitrogen atom in alkylamines, but a near zero lone pair moment to the phosphorus atom in the alkylphosphines. In an earlier treatment ${ }^{8}$ of dipole trends in the alkylphosphines, a large change in the lone pair moment on phosphorus was postulated. This change was presumably a consequence of hybridization changes in phosphorus bonding orbitals. ${ }^{8}$ It is now known, however, that the general increase in molecular moments which this model was designed to explain is erratic. (See Fig. 1). In our hands, the model which attributes a significant lone pair moment to the phosphorus atom of the phosphines cannot be brought into agreement with existing precision microwave and vapor phase dipole moment data for the methylphosphines as well as solution data for other members of the series.

By continuing the method of analysis used earlier, ${ }^{2}$ the molecular dipole moments for the propylphosphines have been reduced to bond dipole moments. It is assumed in such calculations that bond angles are the same as those in the methyl- and ethylphosphines, ${ }^{2}$ that the moment due to the $\mathrm{P}-\mathrm{H}$ bond remains con-

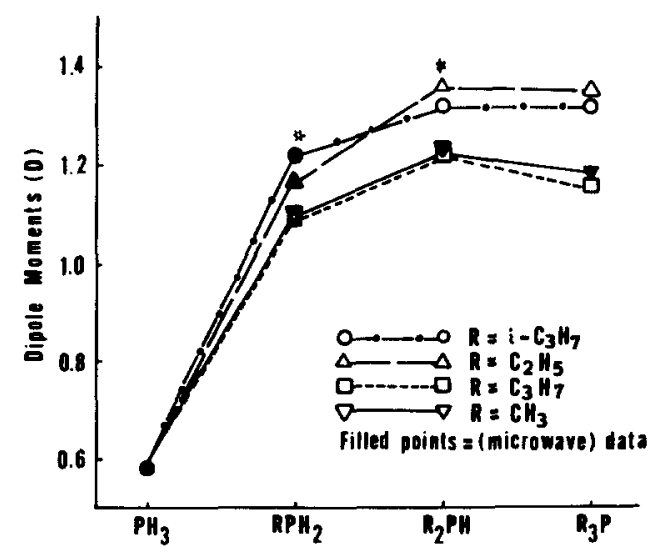

FIG. 1. Dipole moments of alkylphosphines. $*$ Solid points represent measurements in the vapor phase. $\neq$ Open points represent $\mu_{\mathrm{ell}}$. 
stant at $0.355 \mathrm{D},{ }^{2}$ and that the lone pair moment is zero. These three assumptions then demand that a given $\mathrm{P}-\mathrm{R}$ moment will differ as one proceeds from a primary to a tertiary phosphine. The P-R moments for the propylphosphines resulting from this analysis are: $n$ $\mathrm{C}_{3} \mathrm{H}_{7} \mathrm{PH}_{2}, \mu_{\mathrm{P}-\mathrm{R}}=1.08 \mathrm{D} ;\left(n-\mathrm{C}_{3} \mathrm{H}_{7}\right)_{2} \mathrm{PH}, \mu_{\mathrm{P}-\mathrm{R}}=0.95 \mathrm{D}$; $\left(n-\mathrm{C}_{3} \mathrm{H}_{7}\right)_{3} \mathrm{P}, \mu_{\mathrm{P}-\mathrm{R}}=0.81 \mathrm{D} ; i-\mathrm{C}_{3} \mathrm{H}_{7} \mathrm{PH}_{2}, \mu_{\mathrm{P}-\mathrm{R}}=1.23 \mathrm{D}$; $\left(i-\mathrm{C}_{3} \mathrm{H}_{7}\right)_{2} \mathrm{PH}, \mu_{\mathrm{P}-\mathrm{R}}=1.04 \mathrm{D} ;\left(i-\mathrm{C}_{3} \mathrm{H}_{7}\right)_{2} \mathrm{P}, \mu_{\mathrm{P}-\mathrm{R}}=0.92 \mathrm{D}$. Values for the $\mathrm{P}-\mathrm{R}$ moments of all phosphines studied so far are summarized in Fig. 2. A linear relationship between bond moment and the number of alkyl groups replacing hydrogen is observed for all four families studied. It is also striking that the slope for all four families is very close to the same value. Even more tantalizing is the fact that the data fall clearly on two lines. One is for the methyl and $n$-propylphosphines; the second is for ethyl and $i$-propylphosphines. As the figures below show, the methyl and $n$-propylphosphines have an odd number of carbons in any chain attached to phosphorus while the ethyl and $i$-propylphosphines have an even number for the maximum length of the carbon chain beginning at $P$. As yet the significance of this observation (if any) is not clear but the data, obtained by completely independent dipole measurements (microwave, heterodyne-beat on vapor, and solution) show an unequivocal division into two groups.<smiles>CCP</smiles>

Ethyl

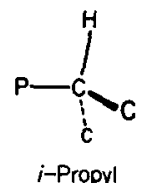

Even choin

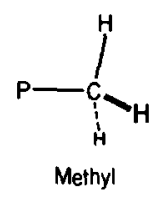

Odd chain

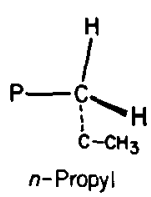

-Propyl
The general decrease in $\mu_{P-R}$ with increasing alkyl substitution can be easily rationalized in terms of an increase in the polarizability (increase in polarizability corresponds to a loosening of the electron cloud) of the electron cloud on the phosphorus as each proton is replaced by an alkyl group. A more polarizable cloud would be able to shift further toward the carbon thus reducing the charge separation and the $P-R$ dipole moment. The resulting $\mu_{P-R}$ line should then fall with increasing alkyl substitution. The trend is confirmed in Fig. 2.

Attempts to correlate the $\mu_{\mathrm{P}-\mathrm{R}}$ bond moments with Taft $\sigma$ values, ${ }^{9}$ representing the inductive effect of the alkyl group attached to phosphorus, have not been definitive. For example, in the primary phosphines, the methyl group with a Taft $\sigma$ value of $0.00^{9}$ shows a $\mathrm{P}-\mathrm{R}$ moment of $1.06 \mathrm{D}$ while the slightly more electron releasing ethyl group, with a $\sigma$ value of -0.10 gives a slightly larger bond moment of $1.17 \mathrm{D}$. Similarly the $\sigma$ value of -0.19 for the isopropyl group predicts a $\mathrm{P}-\mathrm{R}$ moment in the neighborhood of the observed value of $1.23 \mathrm{D}$. On the other hand these same argu-

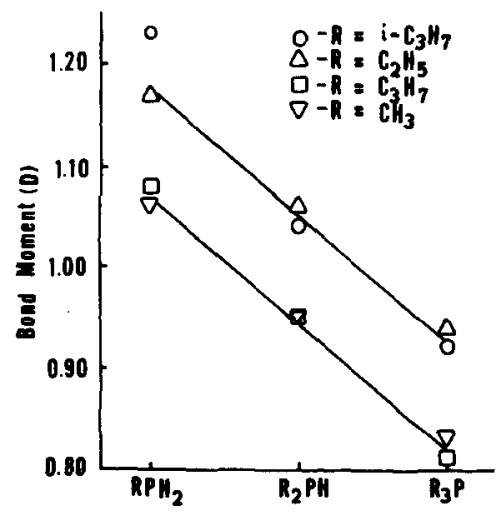

FIG. 2. P-R bond moments in methyl, ethyl, propyl, and $i$-propylphosphines.

ments would predict that the $n$-propyl group with a $\sigma$ value of -0.12 should fall somewhat above the ethyl group (perhaps $1.19 \mathrm{D}$ ). The experimental value of $1.08 \mathrm{D}$ is much too low, falling very close to the value for the methyl group. Apparently $\sigma$ values based on acidity and rate measurements from solution either are not sufficiently sensitive to correlate with the small electron displacements revealed by bond dipoles or relate to a somewhat different phenomenon. Correlations with other parameters are being explored and will be considered in a subsequent paper.

\section{EXPERIMENTAL}

\section{Materials}

(a) Isopropylphosphine, $i-\mathrm{C}_{3} \mathrm{H}_{7} \mathrm{PH}_{2}$, was prepared using a method developed by Spielvogel ${ }^{10}$ and based on the work of Kinnear and Perren. ${ }^{11}$ The equations are:

$$
\begin{gathered}
\mathrm{AlCl}_{3}+\mathrm{PCl}_{3}+i-\mathrm{C}_{3} \mathrm{H}_{7} \mathrm{Br} \rightarrow\left[i-\mathrm{C}_{3} \mathrm{H}_{7} \mathrm{PCl}_{3}\right]\left[\mathrm{AlCl}_{3} \mathrm{Br}\right] . \\
{\left[i-\mathrm{C}_{3} \mathrm{H}_{7} \mathrm{PCl}_{3}\right]\left[\mathrm{AlCl}_{3} \mathrm{Br}\right]+\mathrm{LiAlH} \mathrm{diglyme}_{4}^{\longrightarrow} i-\mathrm{C}_{3} \mathrm{H}_{7} \mathrm{PH}_{2}} \\
+\mathrm{AlCl}_{3}+\mathrm{LiCl}+\mathrm{H}_{2} .
\end{gathered}
$$

The product showed a single peak in the vapor phase chromatogram. Anal. Calc for $\mathrm{C}_{3} \mathrm{H}_{9} \mathrm{P} ; \mathrm{C}, 47.3 \% ; \mathrm{H}$, $12.0 \%$; mol wt 76.1 . Found ${ }^{12}$ : C, $46.96 \%$; H, $11.72 \%$; mol wt by vapor density, 75.1. Details of the procedure and characterization are given elsewhere. ${ }^{10 \mathrm{~b}}$

(b) Diisopropylphosphine was prepared by an extension of the procedure for $\left(\mathrm{CH}_{3}\right)_{2} \mathrm{PH}^{13}$ using $i-\mathrm{C}_{3} \mathrm{H}_{7} \mathrm{Br}$ and $\mathrm{NaPH}_{2}$ in liquid ammonia. The product was purified by vacuum distillation: $\mathrm{mp}-95^{\circ} \pm 1$. Anal. calc for $\mathrm{C}_{6} \mathrm{H}_{15} \mathrm{P}: \mathrm{C}, 61.0 \% ; \mathrm{H}, 12.8 \%$. Found: $\mathrm{C}, 60.92 \%$; H, $12.59 \%$. See Ref. $10 \mathrm{~b}$.

(c) Triisopropylphosphine was prepared by the reaction of $i$ - $\mathrm{C}_{3} \mathrm{H}_{7} \mathrm{MgBr}$ with $\mathrm{PCl}_{3} \cdot{ }^{14}$ After vacuum distillation the product was converted to the hydrochloride salt from which the pure phosphine was dis- 
TABLE II. Gas phase dielectric data for primary propylphosphines.

\begin{tabular}{ccc}
\hline \hline$T\left({ }^{\circ} \mathrm{K}\right)$ & $\begin{array}{c}(\Delta C / \Delta P)_{0}{ }^{\mathrm{a}} \times 10_{3} \\
(\mathrm{pf} / \mathrm{mm})\end{array}$ & $\begin{array}{c}\text { Molar } \\
\text { polarization }\end{array}$ \\
\hline${ }_{n}-\mathrm{C}_{3} \mathrm{H}_{7} \mathrm{PH}_{2}$ & & \\
278.08 & 2.230 & 60.43 \\
286.11 & 2.120 & 59.11 \\
294.39 & 2.028 & 58.18 \\
303.11 & 1.954 & 57.73 \\
313.25 & 1.880 & 57.40 \\
323.10 & 1.794 & 56.50 \\
& & \\
$P_{T}=(24.2 \pm 2.8)+(7176 \pm 824) / T$ \\
& & \\
$i-\mathrm{C}_{3} \mathrm{H}_{7} \mathrm{PH} \mathrm{H}_{2}$ & & \\
270.50 & 2.320 & 61.15 \\
278.06 & 2.225 & 60.29 \\
286.04 & 2.145 & 59.79 \\
294.53 & 2.040 & 58.55 \\
303.47 & 1.948 & 57.62 \\
313.23 & 1.855 & 56.61 \\
& & \\
$P_{T}=(27.8 \pm 1.5)+(9061 \pm 445) / T$ \\
\hline
\end{tabular}

s $(\Delta C / \Delta P)_{0}$ is the ratio of the change in condenser reading to the corresponding pressure change in the cell extrapolated to zero pressure. The total molar polarization at each temperature was calculated as $P_{T}=\left(760 R T / 3 \times 273.2 C_{0}\right)(\Delta C / \Delta P)_{0}$ where $C_{0}$ is the capacitance of the evacuated cell. The equations shown result from a least squares treatment of the data.

placed by ammonia: $\mathrm{mp}-72 \pm 2^{\circ}$. Anal. Calc for $\mathrm{C}_{9} \mathrm{H}_{21} \mathrm{P}$ : $\mathrm{C}, 67.5 \% ; \mathrm{H}, 13.2 \%$. Found: $\mathrm{C}, 66.2 \%, \mathrm{H}, 12.9 \%$. The low analytical results are consistent with past literature reports.

(d) $n$-Propylphosphine was prepared from $n-\mathrm{C}_{3} \mathrm{H}_{7} \mathrm{Br}$ and $\mathrm{NaPH}_{2}$ in liquid ammonia. ${ }^{13}$ Anal. calc for $\mathrm{C}_{3} \mathrm{H}_{9} \mathrm{P}$ : C, $47.3 \% ; 12.0 \%$; mol wt 76.1. Found: $\mathrm{C}, 44.49 \%$; $\mathrm{H}$, $11.44 \%$; mol wt (vapor density) 77.4. Analytical problems were extreme, but purity was established by NMR and ir.

(e) Di-n-propylphosphine was prepared by a proce- dure of Niebergall and Langenfeld ${ }^{15}$ using the following reactions:

$$
\begin{aligned}
& \begin{aligned}
\underset{2}{2} \mathrm{PSCl}_{3}+6 \mathrm{C}_{3} \mathrm{H}_{7} \mathrm{MgBr} \stackrel{\text { ether }}{\longrightarrow}\left(\mathrm{C}_{3} \mathrm{H}_{7}\right)_{2} \mathrm{P}-\mathrm{S} & \stackrel{\mathrm{P}}{\mathrm{P}}\left(\mathrm{C}_{3} \mathrm{H}_{7}\right)_{2} \\
& +\mathrm{MgX}_{2}+\mathrm{C}_{6} \mathrm{H}_{14}
\end{aligned}
\end{aligned}
$$

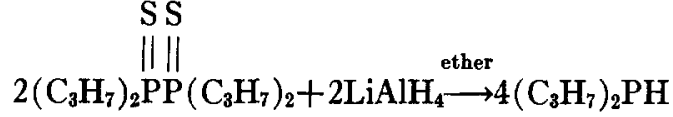

$$
\begin{aligned}
& +\mathrm{Li}_{2} \mathrm{~S}+\mathrm{Al}_{2} \mathrm{~S}_{3}+\mathrm{H}_{2} \text {. }
\end{aligned}
$$

The product was purified by fractional distillation: $\mathrm{mp}-95 \pm 1$. Anal. calc for $\mathrm{C}_{6} \mathrm{H}_{15} \mathrm{P}: \mathrm{C}, 61.0 \% ; \mathrm{H}$, $12.8 \%$. Found: $\mathrm{C}, 60.94 \% ; \mathrm{H}, 12.67 \%$.

(f) Tri- $n$-propylphosphine was prepared from $\mathrm{PCl}_{3}$ and $\mathrm{C}_{3} \mathrm{H}_{7} \mathrm{MgBr} .{ }^{16}$ The product was purified by vacuum distillation: $\mathrm{mp}-83 \pm 1$. Anal. calc for $\mathrm{C}_{9} \mathrm{H}_{21} \mathrm{P}: \mathrm{C}$, $67.5 \%$; H, 13.2\%. Found: C, $65.4 \% ; \mathrm{H}, 12.9 \%$. Details of all preparations are given in Ref. $10 \mathrm{~b}$.

(g) Solvent benzene for the dielectric measurements was frozen then partially melted and the fluid decanted. Sodium hydride was added to the remaining portion after melting and the mixture was stirred for $24 \mathrm{hr}$. It was then distilled under vacuum into a reservoir which was subsequently brought to $1 \mathrm{~atm}$ under dry nitrogen gas. Solvent was delivered to the sample bulbs under nitrogen pressure so that neither sample nor solvent was subsequently exposed to the atmosphere.

All commercial chemicals and solvents used were reagent grade. Alkylhalides were vacuum distilled before use.

\section{Gas Phase Measurements}

The orientation polarizations of $n-\mathrm{C}_{3} \mathrm{H}_{7} \mathrm{PH}_{2}$ and $i-\mathrm{C}_{3} \mathrm{H}_{7} \mathrm{PH}_{2}$ were determined in the gas phase using a precision heterodyne beat dielectric apparatus. ${ }^{17}$ Measurements were made at six temperatures with 15-30 measurements at each temperature at pressures ranging from $50-260 \mathrm{~mm}$. The resulting data at each temperature were extrapolated to zero pressure to correct for deviation from ideal gas behavior.

TABLE III. Dielectric constant data for propylphosphines in benzene.

\begin{tabular}{lcccc}
\hline \multicolumn{1}{c}{ Sample } & \multicolumn{1}{c}{$\alpha^{\mathrm{a}}$} & $\beta^{\mathrm{a}}$ & \multicolumn{2}{c}{$\begin{array}{c}\text { Orientation } \\
\text { polarization }\end{array}$} \\
\hline$n-\mathrm{C}_{3} \mathrm{H}_{7} \mathrm{PH}_{2}$ & $1.60 \pm 0.13$ & $-0.122 \pm 0.003$ & $-0.2103 \pm 0.007$ & $24.45 \pm 1.94$ \\
$\left(n-\mathrm{C}_{3} \mathrm{H}_{7}\right)_{2} \mathrm{PH}$ & $2.07 \pm 0.14$ & $-0.165 \pm 0.011$ & $-0.2687 \pm 0.0100$ & $31.04 \pm 2.07$ \\
$\left(n-\mathrm{C}_{3} \mathrm{H}_{7}\right)_{3} \mathrm{P}$ & $2.16 \pm 0.27$ & $-0.165 \pm 0.005$ & $-0.3263 \pm 0.0049$ & $32.19 \pm 3.92$ \\
$i-\mathrm{C}_{3} \mathrm{H}_{7} \mathrm{PH}_{2}$ & $1.49 \pm 0.06$ & $-0.122 \pm 0.012$ & $-0.2414 \pm 0.0039$ & $23.37 \pm 1.07$ \\
$\left(i-\mathrm{C}_{3} \mathrm{H}_{7}\right)_{2} \mathrm{PH}$ & $2.42 \pm 0.52$ & $-0.170 \pm 0.013$ & $-0.3085 \pm 0.0046$ & $36.88 \pm 7.68$ \\
$\left(i-\mathrm{C}_{3} \mathrm{H}_{7}\right)_{3} \mathrm{P}$ & $2.46 \pm 0.13$ & $-0.117 \pm 0.011$ & $-0.2280 \pm 0.0120$ & $37.69 \pm 1.92$ \\
\hline
\end{tabular}

a $\alpha, \beta$, and $\gamma$ are the change in dielectric constant, density, and refractive index squared with mole fraction solute. 


\section{Measurements in Solution}

Solutions were prepared by distilling a phosphine into the sample bulb under vacuum and adding solvent as described above. The pressure was brought to $1 \mathrm{~atm}$ with dry nitrogen. Samples were forced into a syringe under nitrogen pressure for delivery to the appropriate instrument to avoid any contamination by oxygen or moisture. Sample concentrations were determined by mass measurement and were expressed as mole fraction. Concentrations ranged between 0.005 and 0.025 mole fraction solute. Dielectric constants, densities, and refractive indices of the solutions were all obtained at $25.0^{\circ}$. The dielectric apparatus has been previously described. ${ }^{17 a}$ Refractive indices were obtained with a high precision Abbe' refractometer (Bausch and Lomb) at the $\mathrm{Na}_{D}$ line. Densities were determined using a pycnometer whose volume was calibrated with the solvent benzene assuming a density for benzene of $0.87378 \mathrm{~g} / \mathrm{cc}^{18}$

\section{Data Reduction}

Data from the vapor phase measurements are shown in Table II. The dipole moments were obtained from the slopes of $P_{T}=A+B / T$ as $\mu=0.012812 \mathrm{~B}$, the standard Debye method.

Data from measurements in solution are summarized in Table III. The value $\alpha$ was calculated as $\alpha=\sum\left(\epsilon_{1,2}\right)-$ $n \epsilon\left(\sum x_{2}\right)^{1 / 2}$ where $\epsilon$ is the dielectric constant, $n$ is the number of measurements, $x$ is mole fraction, and the subscripts 1 and 2 refer to solvent and solute, respectively. This method was made for $\alpha$ because the $\epsilon$ values were determined relative to $\epsilon_{1}$ so that $\epsilon=\epsilon_{1}$ at $x_{2}=0$ is a fixed point on the line. $\beta$ and $\gamma$ were determined by least squares. Within the limits of random error, no deviation from linearity of any of the data plots was observed.

The total polarization at infinite dilution was calcu- lated according to Hedestrand's procedure. ${ }^{19}$ For benzene solution at $25.0^{\circ}$ the expression is $P_{T}=0.34086 M+$ $14.692 \alpha-30.472 \beta$ when $M$ is the molecular weight of the solute, $\epsilon_{1}=2.2725,{ }^{20}$ and the density of benzene is $0.87378 \mathrm{~g} / \mathrm{cc}^{8}{ }^{8} \mathrm{~A}$ similar expression was used to calculate the molar refraction at infinite dilution: $R_{0}=$ $0.33557 M-30.000 \beta+14.886 \gamma$, taking $n_{D}^{2} f p r$ benzene as $2.24457 . .^{21}$ Atom polarization was approximated as $0.10 R_{0}$.

* Present address: Department of Chemistry, University of Utah, Salt Lake City, Utah 84112.

${ }^{1}$ J. R. Weaver and R. W. Parry Inorg. Chem., 5, 703 (1966).

2 G. Kodama, J. R. Weaver, J. LaRochelle, and R. W. Parry, Inorg. Chem. 5, 710 (1966)

${ }^{3}$ J. R. Weaver and R. W. Parry, Inorg. Chem. 5, 713 (1966).

$4 \mathrm{~J}$. R. Weaver and R. W. Parry, Inorg. Chem. 5, 718 (1966)

${ }^{5}$ C. W. Cumper, A. A. Foxton, J. Reed, and A. I. Vogel, J. Chem. Soc. 430 (1964).

${ }^{6}$ L. Onsager, J. Am. Chem. Soc. 58, 1486 (1936).

${ }^{2}$ H. Yoneda, Bull. Chem. Soc. Japan 31, 708 (1958).

${ }^{8} \mathrm{R}$. F. Hudson, Structure and Mechanism in Organophosphorus Chemistry (Academic, New York, 1965)

${ }^{9} \mathrm{R}$. W. Taft, Jr. in Steric Effects in Organic Chemistry, edited by M. S. Newman (Wiley, New York, 1956), Chap. 13.

${ }^{10}$ (a) B. F. Spielvogel and R. W. Parry (unpublished results) University of Michigan (1961) ; (b) J. G. Morse, Ph.D. dissertation, University of Michigan, 1966).

"A. M. Kinnear and E. A. Perren, J. Chem. Soc. 1952, 3437.

${ }^{12}$ Analyses were by Spang Microanalytical Laboratory, Ann Arbor, Michigan.

${ }^{13}$ R. I. Wagner and A. B. Burg, J. Am. Chem. Soc. 75, 3869 (1953).

${ }_{14}$ W. C. Davies, J. Chem. Soc., 1043 (1933).

${ }^{15} \mathrm{H}$. Niebergall and B. Langenfeld, Chem. Ber. 95, 64 (1962). ${ }^{16}$ W. C. Davies, P. L. Pearse, and W. J. Jones, J. Chem. Soc. 1262 (1929).

${ }^{17}$ (a) J. R. Weaver, S. Shore, and R. W. Parry, J. Chem. Phys. 29, 1 (1958); (b) J. G. Morse and R. W. Parry, ibid. 46, 4159 (1967).

${ }^{18}$ R. J. W. LeFevre, Dipole Moments (Methuen, London, 1958), p. 46.

${ }^{19}$ G. Hedestrand, Z. Physik. Chem. 2B, 428 (1929) ; F. Daniels, J. H. Mathews, J. W. Williams, P. Bender, and R. A. Alberty, Experimental Physical Chemistry (McGraw-Hill, New York, 1956), p. 210

${ }_{20}$ Reference 19, p. 2.

${ }^{21}$ Reference 19, p. 55. 